\title{
Teachers' Adaptions of the Percentage Bar Model for Creating Different Learning Opportunities
}

\author{
Christian Büscher ${ }^{1 *}$ (D) \\ ${ }^{1}$ TU Dortmund University, GERMANY \\ *Corresponding Author: christian.buescher@tu-dortmund.de \\ Citation: Büscher, C. (2021). Teachers' Adaptions of the Percentage Bar Model for Creating Different Learning Opportunities. International \\ Electronic Journal of Mathematics Education, 16(3), em0643. https://doi.org/10.29333/iejme/10942

\begin{tabular}{|c|c|}
\hline ARTICLE INFO & ABSTRACT \\
\hline Received: 8 Oct. 2020 & Teachers do not directly implement new teaching materials, but rather adapt them. For changing teaching \\
\hline Accepted: 28 Feb. 2021 & $\begin{array}{l}\text { practice, research requires more insights into these adaptions. This study draws on the Theory of Instrumental } \\
\text { Genesis to describe the ways teachers adopt the percentage bar model to create different learning opportunities. } \\
\text { The results of the exploratory case study show two fundamentally different utilization schemes of the percentage } \\
\text { bar model employed by teachers in the classroom. The utilization scheme of Partitioning and Counting creates } \\
\text { learning opportunities for the conceptual core of percentages and proportional reasoning, whereas the utilization } \\
\text { scheme of Mirror Movement only addresses scaling. Implications include that researchers need to pay close } \\
\text { attention to the utilizations of new teaching materials, and teacher educators need to provide new routines along } \\
\text { with new materials. }\end{array}$ \\
\hline
\end{tabular}

Keywords: case study, instrumental genesis, percentages, teacher practices, teaching materials

\section{INTRODUCTION}

As research has shown again and again, changing teaching practice appears to be a hard problem (Wilkie, 2017). Still, research has also uncovered pathways for changing teaching practice (Century \& Cassata, 2016). One of those pathways is the design and dissemination of innovative teaching materials that have proven effective in research, yet often lack wider implementation. However, this 'material-based' strategy commonly only proves effective for changing practice when combined with other more systemic strategies (Prediger et al., 2019) as well as professional development (Ball \& Cohen, 1996). The reason is that teachers do not simply implement new teaching materials as intended by the designer, but instead adapt it according to their own knowledge, their own teaching practices, and their students' needs (Brown, 2009; Sherin \& Drake, 2009). This can result in impressive classroom-specific utilizations of the materials for problems the designer was unable to anticipate; it can also result in unproductive adaptions that discard the often subtle core ideas of the materials, disabling the beneficial effects intended by the designer and possibly even harming students' understanding.

This latter result of adaptation has prompted researchers to look for robust ways of designing teaching materials. One conceptualisation of such materials is to consider them as 'concretisations' of didactic ideas (Leong et al., 2019). Such concretisations consist of teaching materials that are designed in such a way as to show a high degree of 'comportment', which Leong et al. call the "extent to which the concretisation 'carries' [...] the instructional innovations" (Leong et al., 2019 p. 369). If designed in such a way, Leong and colleagues propose that "it is not possible for the concretisation to be used in the classroom without the participants tapping into the goals it comports" (p. 369).

This creates a demanding challenge for the designer of new teaching materials, as the designer needs to anticipate teachers' adaptions of the new materials. Whereas the general adaptation processes are well-documented from empirical studies (Brown, 2009; Sherin \& Drake, 2009), this study takes a topic-specific approach (Hußmann \& Prediger, 2016). This approach assumes that teachers' actions and goals can vary from topic to topic, based on their pedagogical content knowledge (Ball et al., 2008). Therefore, adaption processes have to be investigated in a topic-specific way by giving close attention to the mathematical content in view. In this study, the mathematical content investigated is percentages, which requires to investigate teachers' adaptions of visual models like the percentage bar model, as will be argued in the following sections.

The following study provides some insights into teachers' adaption processes of the percentage bar model, which is wellestablished in research but has had only seen limited implementation in classrooms. As a theoretical framework, the study proposes to adapt the Theory of Instrumental Genesis (TIG) at a teacher level as a theory of didactic instrumental genesis (similar to Haspekian, 2014). This allows to uncover some mechanisms of adaption observed in a case study observing in the classroom 


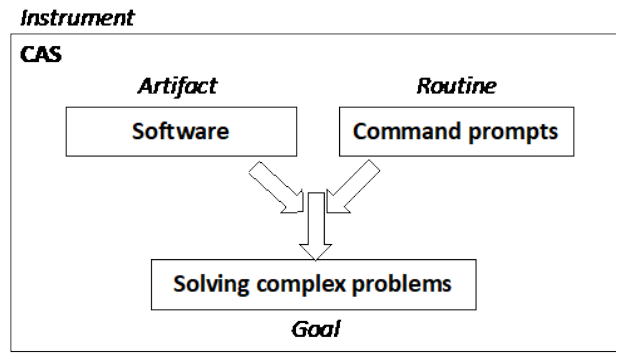

Figure 1. A piece of graphite (artifact) becomes a pencil (instrument) only through certain hand movements (routine) that allow to reach certain goals (expressing thoughts)
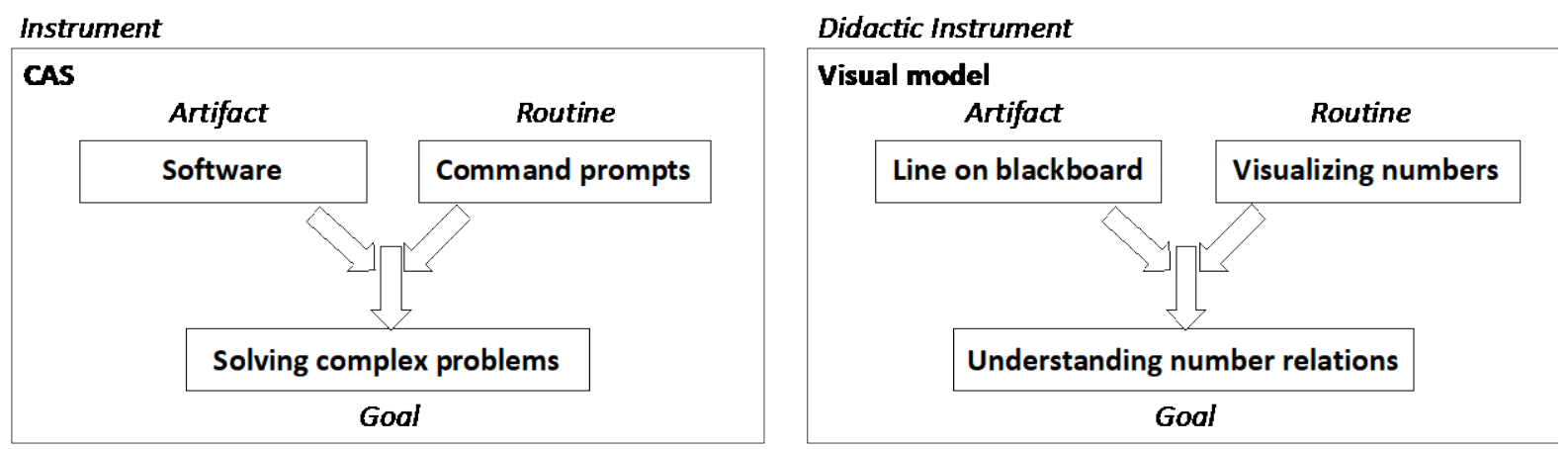

Figure 2. Teachers' didactic instrumental genesis (right) mirrors learners' instrumental genesis (left)

how 13 teachers adapted new teaching materials focusing on the percentage bar model. The results show that most teachers used the new materials, but in very different ways, creating different learning opportunities for their students. One reason given could be that new materials were employed by using old routines. These holdover routines from previous teaching could lessen the benefits of using percentage bar models, explaining one reason for implementations of new materials that fall short of designers' expectations.

\section{THEORETICAL FRAMEWORK}

The Theory of Instrumental Genesis (TIG) was originally used in French didactics to describe the emergence of students' mathematical knowledge while using digital tools such as computer algebra software (CAS) or dynamic geometry software (Drijvers et al., 2013; Rabardel, 2002; Trouche, 2004). However, TIG is also applicable to non-digital or even conceptual tools. A key idea of TIG is the distinction between an instrument (sometimes also called 'tool') and its uses. A CAS has very different degrees of usefulness in the hands of an expert or a novice and thus can be seen as a different instrument for each. In TIG, a physical artefact (a software, a piece of graphite, a piece of wood, ...) becomes an instrument (a CAS, a pencil, a ruler, ...) only through the use of routines (writing command prompts, making writing movements, reading off markings, ...) that allow to reach certain goals (solving complex problems, expressing thoughts, measuring objects, ...). In this way, an instrument is an artifact that is employed by a user making use of routines towards a certain goal (Figure 1). On a larger scale, the uses of instruments are organized in utilization schemes describing the different practices of using instruments.

In learning these routines, two interrelated processes take place. During the process of instrumentalization, the learner adapts the instrument to better fit her needs; during the process of instrumentation, the instrument "prints its mark" (Trouche, 2004, p. 290) on the learner, subtly changing her ways of thinking and acting to be more in line with the tools' affordances and constraints. These processes interact with each other, and in practice cannot be fully separated. In the end, they lead to the emergence of the instrument for the learner, along with mathematical knowledge needed to operate it effectively.

\section{Didactic Instrumental Genesis}

Although the Theory of Instrumental Genesis (TIG) was developed for the learner level, it can also provide insights on the teacher level. As an example, Pepin et al. (2017) used 'documentational genesis', a variant of TIG, for analyzing the resource networks used by teachers for preparing their courses. Shreyar et al. (2010) show how teachers can employ different language moves for utilizing visual models such as the percentage bar model in order to explain meanings or initiate mathematizing processes. In a similar way, this study places the teaching materials that teachers use into the core of their teaching practice.

The teaching materials employed by teachers are here seen as a type of didactic instrument (Figure 2): teachers use artifacts (e.g., a simple line drawn on a blackboard) through use of routines (e.g., marking numbers on the line, posing questions) towards certain didactic goals (e.g., understanding number relations, developing conceptual knowledge). If used in this way, a simple line becomes a visual model (the number line) that can be employed in the utilization schemes making up teacher practices. 
Treating teaching materials as didactic instruments also requires a broadening of the construct of instrument. Whereas TIG mostly refers to specific instruments (a software, a calculator, an online platform), in the hands of skilled teachers, almost any artifact can become a didactic instrument for developing understanding: visual models as well as newspaper articles, photographs, blackboards, problems, and prompts. The status of a didactic instrument depends on the routines available to the teacher. Notably, teaching materials do not work all by themselves; instead, they are didactic artefacts that need to be actively employed towards certain goals. Teachers have certain routines for using didactic artifacts as didactic instruments: initiating single or group work, posing closed or open questions, providing or withdrawing scaffolding, and many others (e.g., Shreyar et al., 2010). Some of these routines can be used for different types of didactic artifacts and different learning contents, some have a single purpose.

When faced with new teaching materials, teachers thus need to engage in didactic instrumental genesis to make didactic instruments out of the new artifacts. Their adaption processes consist of the interwoven dual processes of instrumentation and instrumentalization.

\section{Visual Models as Didactic Instruments}

One special type of didactic instruments are visual models of mathematical concepts. Such visual models (also called representations) are often utilized by teachers to provide 'access' to abstract mathematical ideas. Ball et al. (2008) emphasize the importance of visual models through identifying "recognizing what is involved in using a particular representation" (Ball et al., 2008 , p. 400) as a central task of teaching. Peltenburg et al. (2010) show how visual models such as the number line provide opportunities for special education students to show their mathematical potential (also Peltenburg et al., 2012). Such models can provide a cognitive relief for students, allowing a focus on the mathematically relevant concepts.

However, teachers seem to struggle with the genesis of this type of didactic instrument. Visual models are frequently adapted in an unproductive way, leading to 'learning obstacles' if not adapted well by teachers (Dreher \& Kuntze, 2015). Mitchell et al. (2014) even go as far as to claim that without proper teaching knowledge, "representation use may do more pedagogical harm than good" (p. 57). They identify some knowledge components required for suitable use of representations, such as "knowledge of key student ideas that can be surfaced and remediated while working with representations" (p. 55). It seems that processes of instrumentation and instrumentalization do not automatically lead to productive adaptations of visual models. More insights are needed into the ways how teachers actually adapt visual models for didactic goals like fostering conceptual understanding.

\section{Content-Specificity of Routines}

In recent years, mathematics education research has seen an increased focus on the way teachers act in the classroom. Several conceptualizations for teachers' actions have been proposed by identifying 'core tasks of teaching' (Bass \& Ball, 2004), 'core practices' (Forzani, 2014) or 'high-leverage teaching practices' (Hlas \& Hlas, 2012). These conceptualizations are often formulated on a very general level and form utilization schemes rather than single routines. Routines that implement the general practices of 'choosing and using representations' (Bass \& Ball, 2004) and 'making connections between multiple representations' (Hlas \& Hlas, 2012) would look very differently for percentages than for linear functions. Detailed insights into teachers' implementations of these practices are necessary.

One such example is described by Fauskanger and Mosvold (2017), who give a detailed account of how one teacher engages in the practice of 'explaining and modeling content, practices, and strategies'. Here, the teacher tries to explain the part-of-part meaning of the multiplication of fractions via an area model. Typically, this would entail to illustrate part-whole and part-part relationships within a single rectangle. However, the teacher used one rectangle for each fraction in a procedure unrelated to this meaning of multiplication of fractions. When his students did not understand his explanations, he told his students to memorize the formal calculation procedure instead. Reports such as this illustrate that practices like giving explanations and using visual models can have different implementations, wildly varying in their effects on the conceptual understanding of students. In other words, the specific routines for employing visual models as didactic instruments are content-specific. Research needs to take the situations-specificity of teacher' utilization schemes of didactic instruments into account (Blömeke et al., 2015).

\section{DIDACTIC INSTRUMENTS FOR TEACHING PERCENTAGES}

Investigating didactic instruments requires a topic-specific approach, as teachers' goals and routines are shaped by the content that is taught. Even though conceptual understanding can be considered a goal for many mathematical contents, focused use of didactic instruments needs to identify the relevant content-specific sub-goals that are subsumed under the heading of conceptual understanding. This study proceeds by gathering didactic artifacts, routines and goals from research and practice for teaching percentages.

\section{Goals for Teaching Percentages}

Research on students' conceptions on percentages and their difficulties with solving percentage problems have long been a focus in mathematics education research, although the importance of percentages in the curriculum is not reflected by a corresponding quantity of research reports (Parker \& Leinhardt, 1995). Researchers have documented the difficulty of solving percentage problems (Baratta et al., 2010) as well as students' intuitive resources (Rosenthal et al., 2009). Although specific approaches in instruction on percentages can lead to better performance on percentage tests (Ngu et al., 2014), percentages can still be considered a hard concept for students to learn (Parker \& Leinhardt, 1995). 
Table 1. Different Aspects of percentages for different uses (based on Parker \& Leinhardt, 1995)

\begin{tabular}{lll}
\hline Aspect & Description & Example \\
\hline Number & The expression $p \%$ can be operated on like a number and can be interpreted in & $5 \%=0.05$ \\
& terms of hundredths. & $5 \%{ }^{*} 2=10 \%$ \\
\hline Intensive quantity & The expression $p \%$ can be used to order and compare abstract ratios. & $3 / 8=37,5 \%<40 \%=2 / 5$ \\
\hline Fraction & The expression $p \%$ of $x$ indicates a part of a whole. & "The candidate received 33\% of the vote." \\
\hline Ratio & $\begin{array}{l}\text { The expression } y \text { is } p \% \text { of } x \text { describes a comparison between different sets or a } \\
\text { change of an object, }\end{array}$ & "The new price is $75 \%$ of the old price" \\
\hline
\end{tabular}

Table 2. Central concepts of proportional reasoning for percentage problems

\begin{tabular}{lll}
\hline Task: The new price of $60 €$ is $75 \%$ of the old price. What was the old price? & Procedure \\
\hline Concept & Example & $75 \%: 3=25 \%$ \\
\hline Unitizing & $75 \%$ and $60 €$ can be partitioned into pieces of $25 \%$ and $20 €$. & $60 €: 3=20 €$ \\
\hline Measuring & $100 \%$ consists of 4 pieces of 25\%. & $100: 4=25 \%$ \\
& The old price consists of 4 pieces of $20 €$ & $x: 4=20 €$ \\
\hline Scaling & To find the old price, one needs to take four parts of $20 €$. & $4 * 20 €=80 €$ \\
\hline
\end{tabular}

One explanation for students' difficulties is that percentages can be considered a 'complex' concept with many different aspects (Table 1). Teachers need to provide learning opportunities for all aspects, as an isolated focus on percentages as numbers or fractions does not lead to an understanding of percentages of ratio.

Since ratios are an important aspect of percentages, dealing with percentage problems requires the use of proportional reasoning (Lamon, 2007). For two ratios $a: b$ and $c: d$, proportional reasoning is the type of reasoning employed for two types of problems (Lamon, 2007): comparison problems (which ratio is greater?) and missing-value problems (given three values, find the fourth). Percentages as intensive quantities provide a standardized way to solve comparison problems, whereas percentages as ratios provide ways for solving missing-value problems.

Proportional reasoning is a construct far too large for a single study, integrating ideas of rational number, fraction, ratio and multiplicative structures. Lamon (2007) proposes seven 'central conceptual structures' for supporting proportional reasoning, three of which play an important role for this study: (1) unitizing, dividing a quantity into smaller pieces with which to operate; (2) measuring, filling out a quantity with smaller pieces; and (3) Scaling ('reasoning up and down' in Lamon, 2007), finding equivalence classes to a ratio. These central concepts of proportional reasoning are here seen as the conceptual core of solving missing-value problems for percentages (see also Brown et al., 2020). This is illustrated through an ideal solution path to a problem in Table 2.

Percentages are a complex concept consisting of different aspects and requiring different concepts of proportional reasoning. Teachers need to pay close attention to their approaches to percentage problems in order to build robust understanding. However, not all teaching methods are equally suited to support these conceptual foundations. To study adaption processes for percentages, the routines employed by the teachers have to be related to the dominant approaches for teaching percentages in the country under study.

\section{Routines and artifacts for teaching percentages in Germany}

Parker and Leinhardt (1995) outline five different methods used by teachers for teaching percentages, two of which have the highest importance for teaching in Germany. In the case method, a given percentage problem is analyzed regarding which of two of the values percentage $P$, base $B$ and rate $r \%$ are given, and which one is desired. This makes three possible cases of given/desired configurations, and for each case a specific routine is then employed. For the example of Table 2, if $P$ and $r \%$ are given, this would prompt an expression of $r$ as decimal 0.r and a calculation of $B$ through $B=P / 0 . r$. The other method relevant to Germany is the unitary analysis method. Here, the ratio of the given values $P: r$ would be proportionally scaled down to units of size 1 (i.e. $P / r: 1)$. This would then be used to measure out the desired value, obtaining $B$ through $B=100^{*} P / r$.

Although Parker and Leinhardt (1995) describe the unitary analysis method as focusing on proportional reasoning, this does not mean that proportional reasoning is an explicit focus in German instruction on percentages. Although research lacks broader insights into current teacher practices for teaching percentages in Germany, the procedures used by students in studies on percentage problems are consistent with the case method or unitary analysis method (Hafner, 2012). Informal discussions with teacher frequently reveal that both methods are commonly employed in heavily ritualized procedures in the classroom. For the case method, identification of what is given consists in looking for textual clues in the problem text (i.e., is there a number followed by the percentage sign?) or making an educated guess. Subsequently, one of the three memorized procedures is then carried out for calculating the desired value. For the unitary analysis method, calculation is carried out in a procedure called rule of three (loosely translated from 'Dreisatz'). This method consists in drawing a table (the 'rule of three table') with two columns and then carrying out the unitary analysis method (Table 3). This is often learned by rote, with rules such as you have to divide by the number on the top left to get to the $1 \%$ without explicitly drawing on the underlying proportional relationships.

Carried out with a purely procedural focus, these didactic instruments do not provide learning opportunities for the concepts such as unitizing, measuring, or scaling. Teachers in Germany need to be supported to include other ways in their teaching for reasoning about percentages. 
Table 3. The case method and rule of three in Germany

Task: The new price of $60 €$ is $75 \%$ of the old price. What was the old price?

\begin{tabular}{l}
\hline Case method \\
\hline $\begin{array}{l}\mathrm{r}=75 \text { because there is a \% sign } \\
\mathrm{P}=60 € \\
\text { Because } r \text { and } \mathrm{P} \text { are given, use the formula } \\
\mathrm{B}=60 / 0.75=80\end{array}$
\end{tabular}

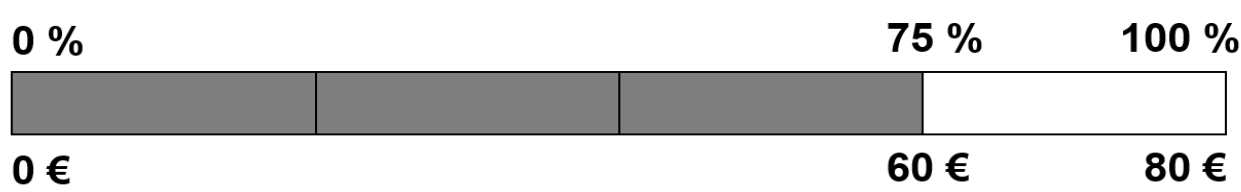

Figure 3. The percentage bar model (Pöhler et al., 2018)

\section{The Percentage Bar Model: A New Artifact for Teachers}

Visual models can be a helpful tool for focusing on the conceptual foundations of proportional reasoning and percentages. For one example concerning proportional reasoning, Orrill and Brown (2012) show how the double number line can support reasoning about the coordination of units through strategies such as partitioning, thus providing a way for unitizing, measuring and scaling. They also note that rote knowledge of memorized procedures such as cross-multiplication can hinder meaningful use of the double number line. This again shows how little conceptual understanding about proportional reasoning is gained through memorization of procedures.

The double number line is extended for percentages in the well-established approach for the percentage bar model (Figure 3), which is extensively used in the approach of Realistic Mathematics Education (van den Heuvel-Panhuizen 2003; van Galen \& van Eerde, 2013). The RME approach focuses on how conceptual knowledge of percentages can emerge through learners' activity with the tool of the percentage bar model (called 'model' in RME, see Gravemeijer 1999). Studies indicate that teaching-learning environments making use of the percentage bar model can be very successful in fostering conceptual understanding of percentages (Pöhler \& Prediger, 2015; van Galen \& van Eerde, 2013).

The percentage bar model does not only provide a procedure for solving percentage problems (reasoning don and up on the double scale), but can be used as a visual model for understanding situations involving percentages (Pöhler \& Prediger, 2015). Its intended use differs from the case method in that the goal is not the mapping of numbers given in a percentage problem to formal percentage terms. Instead, it is used to visualize the relations (as fractions and ratios) between the given numbers, opening the way for intuitive reasoning. And instead of following a fixed calculation procedure as in the rule of three, it allows for flexible unitizing, measuring and scaling of the percentage bar model. As such, the percentage bar model provides an approach to percentages that has shown promising results in research. Yet, although research on the percentage bar model has been carried out for more than 20 years and has shown overwhelmingly positive results in laboratory as well as in classroom settings (e.g., Gravemeijer, 1999; Pöhler \& Prediger, 2015; van Galen \& van Eerde, 2013) its effect on classroom practice has so far been found lacking (Gravemeijer et al., 2016). More insights are needed into how teachers employ new artifacts such as the percentage bar model, how they can be supported, and in what ways new models can shape their practice.

\section{RESEARCH QUESTIONS}

This study has argued that new teaching materials are not directly implemented, but often adapted by teachers (Brown, 2009; Sherin \& Drake, 2009). These adaption processes can be conceptualized as processes of didactic instrumental genesis (Pepin et al., 2017), and different teachers can use the same didactic artifact for different goals and with different routines, creating different didactic instruments. Topic-specific research is needed into the ways these processes of didactic instrumental genesis take place.

This topic-specific study focuses on the content of percentages. As argued, instruction on percentages in Germany often takes a quite ritualized form using mostly the didactic artifact of the rule of three table with a heavy procedural focus. Innovative materials like the percentage bar model could help teachers to promote conceptual understanding about percentages through concepts like unitizing, measuring and scaling instead. Yet, it is unclear how teachers in Germany adapt the percentage bar model, i.e., which routines they employ and for which goals (Figure 4).

This study thus engages the following research questions:

(RQ1) What are the routines employed by teachers adapting the percentage bar model in missing-value problems and for which goals are they suitable?

(RQ2) What are utilization schemes in which the routines are organized and what are the differences in provided learning opportunities through these schemes? 

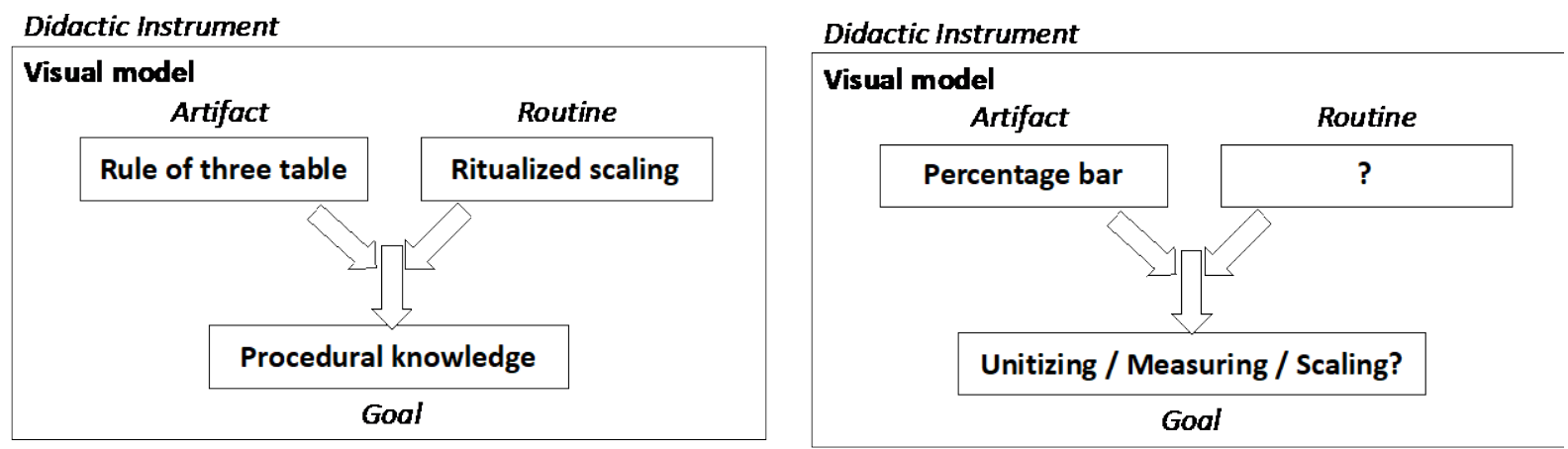

Figure 4. In contrast to the rule of three table, the percentage bar model needs new didactic instrumental genesis in Germany

\section{METHODOLOGY}

\section{Research Context}

This study is part of a larger research project based at TU Dortmund University in Germany, which investigates the design and effects of a professional development (PD) course for inclusive mathematics education on percentages (Prediger et al., 2020, Prediger \& Buró, submitted). In the project, an inclusive teaching unit for Grade 7 classrooms was developed that made heavy use of the percentage bar model, along with supplementary teacher manuals outlining the central ideas of the teaching unit as well as possible instructional approaches for its implementations (Pöhler \& Prediger, 2015; Pöhler et al., 2018). The larger project aims at investigating the professional development of a group of teachers with a wide range of experience and in different stages of professional development concerning inclusive mathematics education on percentages. However, this paper does not include the aspect of inclusion in order to focus on the didactical instrumental genesis of the percentage bar model.

As not much is known about teachers' adaptation of the percentage bar model, this study adopts the approach of an exploratory case study (Yin, 2002). Exploratory case studies provide 'rich descriptions' of phenomena in order to illustrate and to document their inner workings, without necessarily providing explanations. Central to the design of an exploratory case study is the selection of meaningful cases for comparison, which should be distinct enough from each other to allow insights into their differences, yet not so far apart as to be incomparable. In this study, the cases are provided through teachers with a diverse background in mathematics education, who all employed the didactic materials developed by the research team. Thus, all teachers received new didactic artifacts - but still needed to engage in didactic instrumental genesis for their own classrooms.

\section{Participants and Data Collection}

In the larger project, 50 teachers with a diverse range of experience participated in PD courses on inclusive teaching of percentages. Participation was voluntary and open to all teachers of the Dortmund area. These teachers implemented the provided teaching unit on percentages in their own classes, with one half of the group within March to June 2018, and the other half within October 2018 to March 2019. Out of these 50 teachers, 13 teachers volunteered to have some of their lessons with the teaching unit in Grade 7 recorded on video by the team of researchers. All 13 teachers were included in the data collection, and the recordings were carried out by the researchers' teams with multiple cameras and microphones, allowing to observe the teachers' full interactions with all of their students in the classroom while teaching (on average 29 students per class). This resulted in 18 recorded lessons (19 hours of video, of which 3 hours had to be discarded due to technical malfunctions). The recorded lessons did not line up at the same exact moment in the course sequence. As such, different tasks of the course materials were employed by the teachers in different recorded lessons, allowing for a wider observation of different routines.

\section{Data Analysis}

Out of these lessons, the segments in which whole-class discussions took place were identified and transcribed using a standardized transcription manual. The segments consisted of classroom discussions, teacher-centered explanations, as wells as of students' presentations of results. Data analysis then consisted of a multi-step inductive-deductive analysis similar to the approach of qualitative content analysis (Mayring, 2000). Whereas other variants of TIG focus on the way teachers construct resource networks (the documentational approach, Pepin et al., 2017), the methodological approach chosen here focused on the processes of instrumentalization and instrumentation of a single didactic instrument for the teachers (similar to the 'professional instrumental genesis', Haspekian, 2014). First, the employed routines of each teacher were identified. Through comparing and contrasting the routines of different teachers, a set of consolidated routines could be constructed that then could serve as an analytical tool for deductively comparing all different teachers. Thus, the results include the reconstructed routines as well as their occurrences in the different cases of the case study. Teachers' utilization schemes were then identified based on similarities and differences in teachers' employment of routines.

The deductive analysis was conducted using a standardized coding manual, which described the conditions for identifying a routine as well as special cases. In some cases, the routines employed by students during student presentations were also coded as routines employed in the classroom, even if the teacher did not directly demand the use of such routines. This decision was 


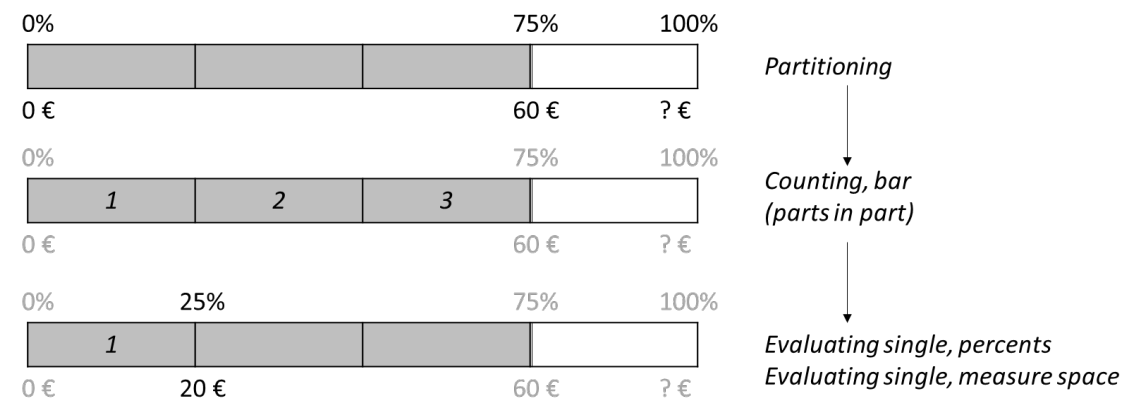

Figure 5. Patricia starts by partitioning, counting parts in part on the percentage bar model, and evaluating single boxes on both scales

made on the assumption that any routines employed by students that are tacitly acknowledged by the teacher (i.e., not explicitly labeled as wrong) are also indications of the routines for utilizing the percentage bar model used by the teacher. The same was true when routines were enacted by the students, but were obviously standard answers to teacher questions (e.g., "what do you have to do now?" - "partition the percentage bar model"). Another decision was that routines for the percentage bar model were only identified when a percentage bar model was explicitly used as a visual model accessible to the whole class (e.g., on the blackboard or a projector), and not when only talking about the abstract construction of percentage bar models.

\section{RESULTS}

For giving examples for the identified routines, two cases of teachers employing different routines for the percentage bar model are shown here in detail. The two teachers employed routines that were frequently used by all teachers, but with different emphasis on certain routines. The two cases shown here were chosen because they represent two fundamentally different utilization schemes of the percentage bar model: (1) Partitioning and Counting and (2) mirroring movement on two scales.

\section{The Utilization Scheme of Partitioning and Counting}

The first case takes place in the classroom of Patricia (pseudonym). The class is a few weeks into the new materials, and has already learned to use percentage bar models to structure situations involving percentages. However, the use of the percentage bar model is far from consolidated and still gives cause for discussion. The episode starts when Patricia poses the problem: "The new price is $60 €$, which is $75 \%$ of the old price. How much is the old price?". She also has prepared a percentage bar model which is already structured into four equal parts.

1 P Which number do we have to write here [base on percentage bar model]? Because the $75 \%$ and $60 €$ are correct. Student 1.

2 S1 $125 €$. Um, yes.

$3 \mathrm{P} \quad$ Student 2.

4 S2 $80 €$.

5 P Student 3.

6 S3 l'd also say $80 €$.

$7 \quad \mathrm{P} \quad$ Well, I want to know how you got the 80. Student 4.

8 S4 Steps of 20.

$9 \quad \mathrm{P} \quad$ Student 5, please explain. Student 4 said that we did steps of 20.

10 S5 Well, that's correct. It's 4 times, no. 20, 3 times 60 , um, 3 times 20 is 60.4 times 60 is 80 , um 4 times 20.

$11 \mathrm{P} \quad \mathrm{I}$ see! Here we have $60 €$ [points to percentage on percent bar]. Until there we did three steps [subsequently knocks on each of the first three parts of the percentage bar model]. How big, then, is every step here below?

[...]

14 S6 $25 \%$.

15 P It's - $25 \%$ is one box. So, here we can write $25 \%$ [...] what would I have do write here below [points to $€$-scale on percentage bar model]? Student 7.

16 S7 20\%. Um, 20\%, well $20 €$.

$17 \mathrm{P} \quad 20 €$ [marks $20 €$ on percentage bar model]. But I still don't know how we found the $20 €$.

In this closely-managed discussion, Patricia tries to guide the students to central insights into percentages for a missing-value problem that seems difficult for the students: finding the base, given rate and percentage. She does this by employing different routines (Figure 5). 


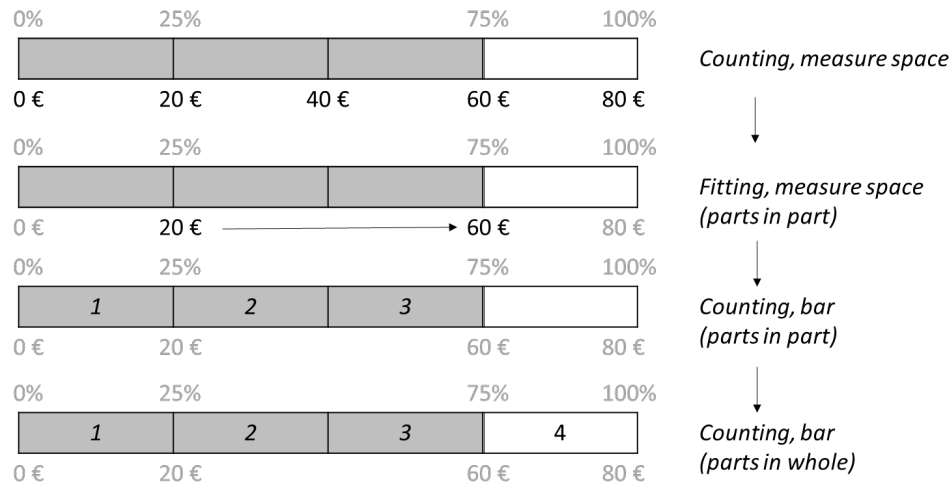

Figure 6. Patricia emphasizes counting

She starts by introducing a percentage bar model she has already partitioned. Although some students are able to find a correct answer (\#4, \#6), her goal is not to find this answer, but to rather let students elaborate their reasoning. When the students introduce an idea of counting in steps (\#8,\#10), she remodels this routine of counting: the part is made up of three steps (\#11) or boxes (\#15). This counting routine is performed on the percentage bar model, not on the numbers, as Patricia explicitly refers to the partitioning of the bar (the 'boxes', \#15). After counting, she uses the boxes for evaluating a single box for both scales of the percentage bar model, the percents (a single box is $25 \%$ ) and the measure space (a single box is $20 €$ ). This evaluation, however, does not seem to be a routine Patricia considers standardized, as she marks the box of $20 €$ to still require explanation (\#17).

In the following, a few students try to provide explanations, none of which satisfy Patricia. Then, Student 7 again takes part in the discussion.

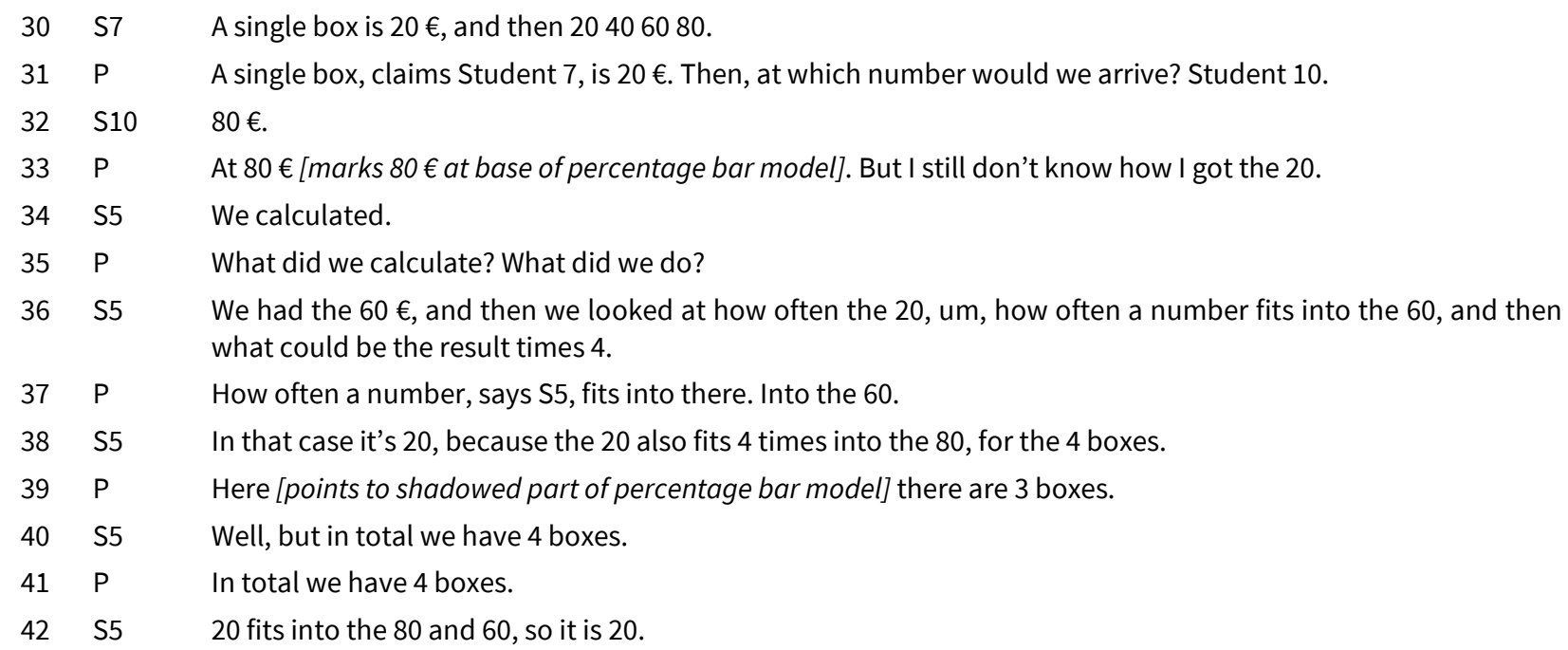

Student 7 shows the routine of counting the units in the measure space, which is accepted by Patricia (\#30, \#33). Still, she demands an explanation of why a single box consists of $20 €$. In the exchange with Student 5, Patricia employs the routine of counting multiple times, but with different nuances (Figure 6). She first talks about fitting the part of $20 €$ in the measure space (\#37), and then differentiates between counting the parts-in-part or parts-in-whole on the percentage bar model (\#39, \#41).

The explanation that 20 fits into 60 and 80 given by Student 5 does again not satisfy Patricia, as this does not include any considerations on rate. In the following, she models the desired considerations on the percentage bar model.

$43 \quad \mathrm{P} \quad$ Let's start again from up here, from the percents. Look at the percents. What did we do with the percentage bar model? Student 11.

44 S11 Divided it into parts?

$45 \quad \mathrm{P} \quad$ Right, divided it into different parts. In how many parts did we divide the bar? Student 12.

46 S12 In size 20.

$47 \quad \mathrm{P} \quad$ Is it correct that we divided the percentage bar model into parts of size 20? You have to look above, how many columns do we have?

$48 \quad \mathrm{~S} 12 \quad 4$.

$49 \mathrm{P} \quad$ 4. We do have 4 boxes. Why did we use 4 boxes? Student 14

50 S14 Because 4 times 25 is 100.

$51 \mathrm{P} \quad 4$ times 25 is 100 . And the 25 fit into where? Student 15.

52 S15 Um, into the 75. 


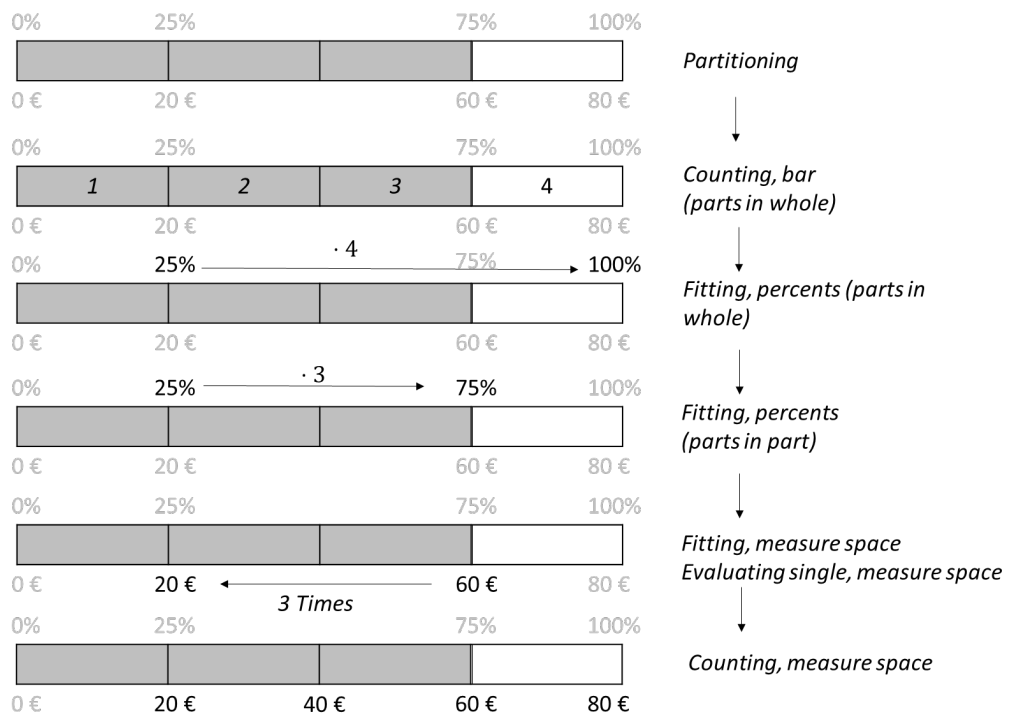

Figure 7. Patricia routines for solving missing-value problems

53 P Correct, into the 75 also. Namely 3 times. Is that correct? Yes, okay. So, 25 fits 3 times into the 75 . What do the 3 have to do with the 60 and our results? Student 16.

54 S16 Because the 20 fits 3 times into the 60.

55 P Right, and that's how we got to the 20. So what kind of steps do we have until the end? Student 7.

56 S7 Of size 20

57 P Of size 20.20406080.

In this very closely-managed interaction, Patricia again draws on the routines already established (Figure 7). She places a strong emphasis on connecting the ideas of counting: how the number of boxes on the percentage bar model (\#49) influences the fitting on the percent scale (\#51), and how this in turn influences the fitting parts on the measure space (\#53), which leads to an evaluation of a single step (\#55, \#56). Finally, a counting routine in units of $20 €$ finds the missing value (\#57).

Throughout the episode, Patricia places a strong focus on Partitioning and Counting the percentage bar model and scales, showing how single routines can be combined in the utilization scheme of Partitioning and Counting. This, however, is not the only possible utilization scheme, as the following example will show.

\section{The Utilization Scheme of Mirror Movement}

This example follows Erich (pseudonym) and his students, who work on the what belongs together? task (Figure 8). The students are asked to allocate short descriptions of situations involving percentages to prepared percentage bar models that already have placeholders for given and desired values. In the course material, this is intended to be worked on late in the course, after the students have had experience with informal strategies for dealing with percentages. They also should have encountered the formal terms base value, percentage, and rate. However, at this point in the course, these formal terms are not yet intended to be fully understood, and are intended to be used only after the situation is structured through percentage bar models.

The discussion shown here starts with Erich who focuses the students on word problem A (see Figure 8).

$7 \quad \mathrm{E} \quad$ Okay, so last week we started with this. Please explain to me what is given. What is given and what is desired? Which terms for percentages do we know, anyway? Maybe we should clarify that first. Student 2.

8 S2 Um, base value is given.

9 E The base value is given, yes.

10 S2 The percentage is given.

[...]

$13 \mathrm{E}$ The percent value, very good. What is the percentage, in this text?

14 S3 Um, 30? Or 100?

15 E 30 what?

16 S3 $30 €$.

17 E $\quad 30 €$, exactly. And the base value, Student 2?

18 S2 Ehm, that are the $50 €$.

19 E That are the $50 €$. So, what is desired? Anybody should be able to answer this one. Student 4.

20 S4 The rate. 


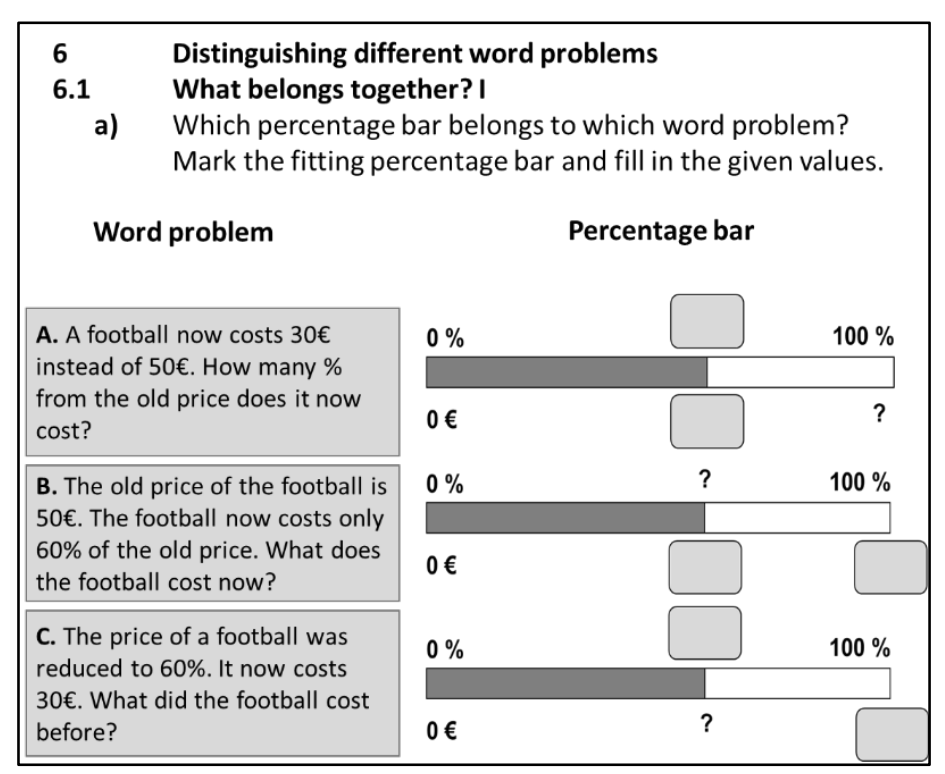

Figure 8. The 'what belongs together?' task (Pöhler et al., 2018)

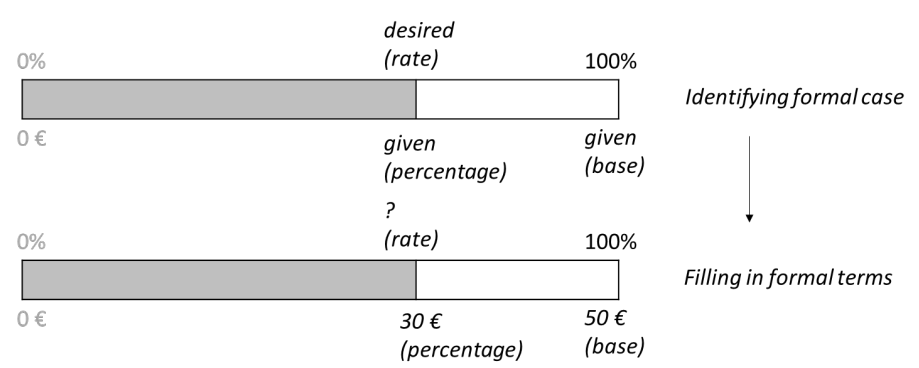

Figure 9. Erich identifies formal terms before filling in the percentage bar model

21 E The rate. [...] Now, which percentage bar model belongs to this word problem? Because there are 3 percentage bar models. Take a moment. Student 4.

$[\ldots]$

24 S4 I would take the second percentage bar model, because where the rate normally is, there is a question mark and that is what's missing.

25 E Very good. [...] What values do I have to fill in, at the percentage bar model? Student 5.

26 S5 Um, below the $100 \%$ are the $50 €$.

27 E Very good. How do we call that?

28 S5 Base?

$29 \mathrm{E} \quad$ That is the base, exactly [...].

In this excerpt, Erich employs the routine identifying formal case, which is not directly utilizing the percentage bar model. In this routine, the students are asked to map values from the word problem to the terms base, percentage, and rate. Student 3 , probably with difficulties in understanding the concepts behind these terms, offers two possible values for percentage (\#14), of which Erich picks the correct one (\#15). With two terms identified, this leaves only the rate as the desired value, as the other possibilities have been eliminated (Figure 9). These terms are then mapped to the percentage bar model on grounds of corresponding missing values. After the terms have been identified, the percentage bar model is filled in with the corresponding values (\#25, \#26).

Through this, Erich shows an instrumentalization of the percentage bar model. The designers of the materials intended that students' would identify the conceptual relationships between the various numbers given in the word problem and structure them using the percentage bar model. Only later was it intended to map connect this with the formal terms. Erich, however adapts the percentage bar to prioritize the formal case.

Afterwards, a student finds the desired rate, but is unable to explain his procedure. This prompts the following exchange.

39 E $60 \%$, very well. How did you find that? Explain how you did it [6s] Okay, who can help?

[...]

43 S9 Ehm, just divide 50 by 10 and then times 6.50 by 10 are 5 , times 6 are 30 . 


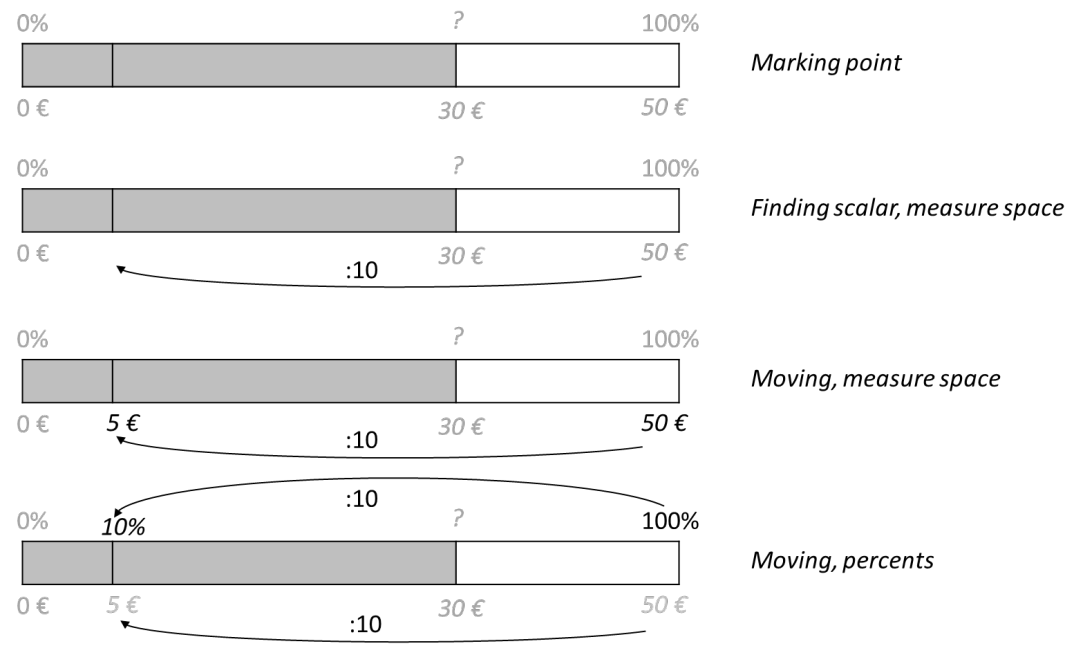

Figure 10. Erich mirrors scaling down of the measure space on the percent scale

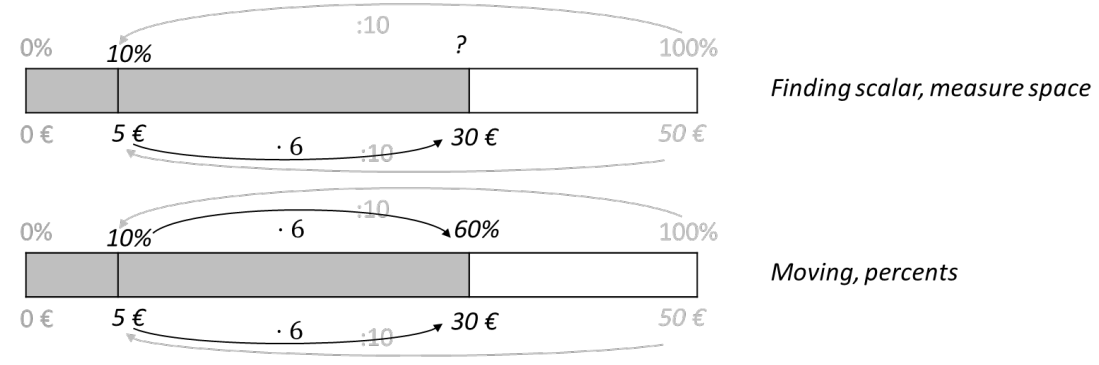

Figure 11. Erich mirrors scaling up of the measure space on the percent scale

$44 \quad E$

Exactly. [...] Now, if one tenth is marked here [draws a bisecting ling an approximately $1 / 10^{\text {th }}$ of percentage bar model], then Student 9 correctly said that we divide by 10 , which gives us $5 €$ [draws an arrow from $50 €$ to the $1 / 10^{\text {th }}$ mark and marks arrow with ' $: 10^{\prime}$ '. Marks ' $5 €$ ' on the lower side at $1 / 10^{\text {th }}$ mark. Draws arrow from $100 \%$ to $1 / 10^{\text {th }}$, marks with ' $\left.: 10^{\prime}\right][\ldots]$

Here, different routines than those of Patricia can be observed (Figure 10). He begins by marking a point on the percentage bar model he designates as $1 / 10^{\text {th }}$, without specifying the whole the fraction relates to or why this specific fraction was chosen. He proceeds by finding a scalar for transforming the $50 €$ to the newly established $1 / 10^{\text {th }}$, yielding a division by 10 , which is then carried out in a routine of moving down to the $50 €$ through division. Afterwards, this movement is mirrored on the percent scale by moving down without further explanation why.

These routines of scaling and mirroring are then continued to find the desired value:

$49 \mathrm{~S} 10 \mathrm{Ehm}$, and to get to the 30, from 5, you have to, ehm, calculate, and ehm, $50 \%$ would be 25 . And 25 plus 5 are, ehm, 30,30 then are $60 \%$.

$50 \mathrm{E} \quad$ [draws arrow from $5 €$ to $30 €$ ] Okay, and if the use the step that Student 9 said? What would you do now?

51 S10 Then you calculate 10 times 6.

52 E Exactly, 10 times 6. Because 10 times 6, ehm, 10 percent times 6 are 60 percent [draws arrow from 10\% to 60\& and marks it with ' ' 6 '] and $5 €$ times 6 are $30 €$ [marks ' 6 ' at the arrow from $5 €$ to $30 €$ ]. Very good.

Student 10 first proposes a different routine for finding the rate by combining different parts of the whole (a part of $25 €$ corresponding to $50 \%$ and a part of $5 €$ corresponding to $10 \%$, \#49). Erich, however, wants to focus the students on the routines already employed earlier (\#50), establishing that the correct procedure is to again find a scalar on the measure space and use that for moving up on the percent scale (\#52). Thus, Erich arrives at the missing value for the percentage problem.

In contrast to the utilization scheme of Partitioning and Counting, Erich does not employ any associated routines. His markings of $10 \%$ and $5 €$ are not intended as indicating the size of a single step or box which can then be counted. Instead, they are points from which to 'get' to another number through multiplicative movement. The fundamental idea of this utilization scheme is that movement on one scale has to also be performed on the other. Because of this, this utilization scheme is given the name of Mirror Movement. 
Table 4. Two utilization schemes of the percentage bar model differ in learning opportunities for conceptual knowledge about proportional reasoning

\begin{tabular}{lll}
\hline Routine & Description & Proportional reasoning \\
\hline Partitioning and Counting & Partitioning the percentage bar model into parts of equal size \\
\hline Partitioning & Assigning a value to a single part of the partitioned percentage bar model \\
\hline Evaluating single & Finding out how often a part fits into another part / a whole & Unitizing \\
\hline Fitting & $\begin{array}{l}\text { Counting in units of single parts of the percentage bar model; also possible to perform } \\
\text { through multiplication }\end{array}$ \\
\hline Counting & Marking a single point on the percentage bar model to represent a point in measure space or - \\
\hline Mirror Movement & percent scale \\
\hline Marking point & Finding a number that can be used in multiplication or division to arrive at another number & Scaling \\
\hline Finding scalar & $\begin{array}{l}\text { Arrow-type movement on a single scale of the percentage bar model through multiplication } \\
\text { or division }\end{array}$ \\
\hline Moving & \\
\hline Other & $\begin{array}{l}\text { Asking questions centered on which two of base, rate and percentage is given, and what is } \\
\text { therefore desired }\end{array}$ \\
\hline Filling in formal terms & Relating positions on the percentage bar model to formal terms \\
\hline
\end{tabular}
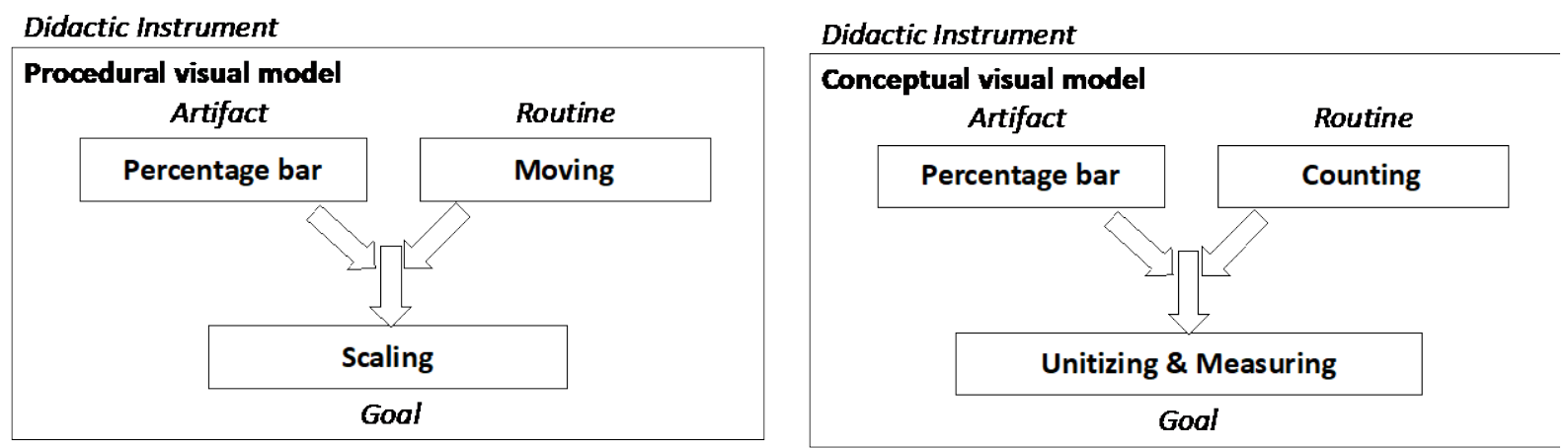

Figure 12. Different didactic instruments emerged from the same didactic artifact

\section{DISCUSSION}

\section{Comparison of Utilization Schemes}

As an answer to Research Question 1, this study identified several routines for utilizing the percentage bar model. Regarding Research Question 2, the cases of Patricia and Erich illustrate how these routines are employed in different utilization schemes of the percentage bar model for missing-value problems, which allow for different learning opportunities. These utilization schemes could be observed across the whole sample, although teachers also mixed different routines and schemes. As each routine creates a different focus on proportional reasoning, these two schemes differ fundamentally in the learning opportunities created for conceptual understanding of proportional reasoning (Table 4).

Patricia showed the utilization scheme of Partitioning and Counting, heavily emphasizing measuring and unitizing. To her, it was not at all self-evident that operations on the percent scale were the same as for the measure space. She stressed the point that the bar shows how percents and measure space were partitioned into the same number of parts, which were of equal relative size, but represented different quantities. She used this to justify that if on took four parts corresponding to $25 \%$, then one should also take four parts corresponding to $20 €$, because one unit is made up of $25 \%$ and $20 €$. Her language revolved around 'fitting' parts or steps into the whole, emphasizing the idea of measurement. In this way, she created learning opportunities for central concepts of proportional reasoning, namely Unitizing and Measuring.

In contrast, Erich chose a utilization scheme that implicitly assumed that operations on one scale have to be mirrored on the other. This mirroring axiom was not explicitly justified. The language employed in these routines revolved around 'getting to' numbers through operations, treating each side of the percentage bar model as a separate number line for arithmetic movement. In this way, he created learning opportunities mostly for the concept of scaling - although it is debatable if these routines represent truly proportional scaling or rather simple multiplicative scaling.

The different utilization schemes show how the teachers' processes of didactic instrumental genesis led to the emergence of two different didactic instruments, although both instruments are based on the same didactic artifact (Figure 12). Erich used the percentage bar model mostly as a visualization for the mirror movements carried out on the isolated scales. Although this could lead to conceptual knowledge about scaling, the percentage bar model was mostly used in a ritualized way for finding missing values. Thus, the didactic instrument that emerged for Erich was a kind of procedural visual model: using the percentage bar model for visualizing procedures for finding missing values. 
On the other hand, Patricia used the percentage bar model for structuring the situation. The missing value to be found was related to its conceptual meaning in a shopping context by making explicit the parts and wholes required for reasoning through unitizing and measuring. In this way, the instrument that emerged for her was a conceptual visual model for reasoning about percentages.

\section{The Possibility of Holdover Routines}

It seems that Patricia and Erich have adapted the percentage bar model in very different ways. The reasons for this could only truly be found in a longitudinal study comparing the routines of a single teacher before and after adapting new materials, which this study is not. Still, comparing the observed routines to the traditional teaching of percentages in Germany illustrated earlier, it seems reasonable to assume that Patricia has changed her routines, whereas Erich has tried to incorporate the new percentage bar model into his old routines. He employs routines such as identifying formal case, which is a routine commonly used in the case method of teaching percentages. He adapts the percentage bar model by filling in the formal terms, although he does not use any formulae and the percentage bar model is designed precisely to allow to understand percentages without using formal terms. For finding the missing values, uses the percentage bar model mostly as visualization of mirrored arithmetic movements, very much in a way teachers traditionally use the rule of three table (Table 3). In this way, he does not draw on the full potential of the percentage bar model for fostering proportional reasoning, as he does not utilize opportunities for partitioning, unitizing, and measuring.

These are tentative interpretations and should not imply that in Erich's classroom, there were no opportunities for building this kind of proportional reasoning. Only a single lesson was observed, which additionally took place quite late in the course. It is entirely possible that Erich actually used the percentage bar model in the intended way earlier, and was now broadening the understanding of his students by including another way of solving missing-value problems. The point of the comparison of utilization schemes is not to make arguments about which teacher performed 'better', but to illustrate the differences of adaptions of the same visual model. This can aid researchers and teacher educators in the professional development of teachers.

\section{CONCLUSION}

Teaching practice can be changed by dissemination of innovative didactic materials (Century \& Cassata, 2016; Prediger et al., 2018). However, research has repeatedly shown that new didactic materials are not directly implemented, but rather adapted by teachers (Brown, 2009; Sherin \& Drake, 2009?). This can result in very different learning opportunities created by teachers. Designers of new materials need to take into account the ways how teachers adapt new materials, so that they can anticipate different uses and provide guidance for teachers. This requires more insights into the mechanisms behind teachers' adaptions of new materials.

This study conceptualized teachers' adaptations of new didactic materials as a process of didactic instrumental genesis, itself an adaption of the Theory of Instrumental Genesis (Drijvers et al., 2013; Rabardel, 2002). The didactic instrumental genesis perspective allows to take into account how the same didactic materials can lead to very different uses of these materials through different utilization schemes composed of different routines for using the materials. This is described through the two central pillars of instrumental genesis, the intertwined processes of instrumentalization and instrumentation (Trouche, 2004). Whereas the former construct describes the process of adopting and adapting a tool for one's goals, the latter describes how the user's goals and concepts are shaped by the instrument itself. With this framework it becomes possible to analyse teachers' adaptions of new didactic materials.

The routines employed by a group of teachers were investigated in an exploratory case study. These teachers with a wide range of experience received new teaching materials utilizing the percentage bar model, a tool for teaching percentages new to most teachers in Germany. Out of their teaching in classrooms, different routines for utilizing the percentage bar model were identified, organized in two larger utilization schemes. In the utilization scheme of Partitioning and Counting, teachers employ a wide range of proportional reasoning. In the utilization scheme of Mirror Movement, most proportional reasoning is replaced by an implicit axiom that multiplicative arithmetic performed on one scale should be mirrored on another. These utilization schemes lead to very different learning opportunities for proportional reasoning.

The results show that it is not enough for researchers to focus on what didactic materials teachers are employing. Instead, the ways how teachers adapt these materials need to be taken into account in order to understand the learning opportunities created in classrooms. Similarly, teacher educators that aim to change practice by providing new teaching materials need to provide new routines and new utilization schemes along with the materials, so that new goals can be reached by the teachers. In this way, teacher educators can support teachers in their didactic instrumental genesis. This study provides a contribution towards this effort by mapping out the routines for developing understanding of percentages with the percentage bar model. However, as these routines are topic-specific, much work remains for further research on other topics.

Author contributions: All authors have sufficiently contributed to the study, and agreed with the results and conclusions.

Funding: The presented study has been conducted within the project Matilda which is financially supported by the German Ministry of Education and Research (BMBF-research grant no. 01NV1704 to S. Prediger and J. Kuhl) in the framework of DZLM, the German Center for Mathematics teacher education (which is financially supported by the German Telekom-Foundation). I thank the principal investigators for the always productive collaboration and their support for this paper.

Declaration of interest: No conflict of interest is declared by authors. 


\section{REFERENCES}

Ball, D. L., \& Cohen, D. K. (1996). Reform by the book: What is: Or might be: The role of curriculum materials in teacher learning and instructional reform?. Educational Researcher, 25(9), 6-8. https://doi.org/10.2307/1177151

Ball, D. L., Thames, M. H., \& Phelps, G. (2008). Content knowledge for teaching: What makes it special?. Journal of Teacher Education, 59(5), 389-407. https://doi.org/10.1177/0022487108324554

Baratta, W., Price, B., Stacey, K., Steinle, V., \& Gvozdenko, E. (2010). Percentages: The effect of problem structure, number complexity and calculation format. In L. Sparrow, B. Kissane, \& C. Hurst (Eds.), Shaping the future of mathematics education (pp. 61-68). Mathematics Education Research Group of Australasia.

Bass, H., \& Ball, D. L. (2004). A practice-based theory on mathematical knowledge for teaching: the case of mathematical reasoning. In J. Wang (Ed.), Trends and challenges in mathematics education (pp. 295-313). East China Normal University Press.

Blömeke, S., Gustafsson, J.-E., \& Shavelson, R. J. (2015). Beyond dichotomies. Zeitschrift für Psychologie, 223(1), 3-13. https://doi.org/10.1027/2151-2604/a000194

Brown, M. W. (2011). The teacher-tool relationship: Theorizing the design and use of curriculum materials. In J. T. Remillard, B. Herbel-Eisenmann, \& G. M. Lloyd (Eds.), Mathematics Teachers at Work (pp. 17-36). Routledge.

Brown, R. E., Weiland, T., \& Orrill, C. H. (2020). Mathematics teachers' use of knowledge resources when identifying proportional reasoning situations. International Journal of Science and Mathematics Education, 18(6), $1085-1104$. https://doi.org/10.1007/s10763-019-10006-3

Century, J., \& Cassata, A. (2016). Implementation research. Review of Research in Education, 40(1), $169-215$. https://doi.org/10.3102/0091732X16665332

Dreher, A., \& Kuntze, (2015). Teachers facing the dilemma of multiple representations being aid and obstacle for learning: Evaluations of tasks and theme-specific noticing. Journal für Mathematik-Didaktik, 36(1), 23-44. https://doi.org/10.1007/s13138-014-0068-3

Drijvers, P., Godino, J. D., Font, V., \& Trouche, L. (2013). One episode, two lenses - A reflective analysis of student learning with computer algebra from instrumental and onto-semiotic perspectives. Educational Studies in Mathematics, 82(1), 23-49. https://doi.org/10.1007/s10649-012-9416-8

Forzani, F. M. (2014). Understanding “core practices" and "practice-based” teacher education. Journal of Teacher Education, 65(4), 357-368. https://doi.org/10.1177/0022487114533800

Gravemeijer, K., Bruin-Muurling, G., Kraemer, J.-K., \& van Stiphout, Irene (2016). Shortcomings of mathematics education reform in the Netherlands: A paradigm case?. Mathematical Thinking and Learning, 18(1), 25-44. https://10.1080/10986065.2016.1107821

Hafner, T. (2012). Proportionalität und prozentrechnung in der sekundarstufe I: Empirische untersuchung und didaktische analysen [Proportionality and percentage calculation in secondary level I: empirical research and didactic analyzes]. Springer. https://doi.org/10.1007/978-3-8348-8668-2

Hlas, A. C., \& Hlas, C. S. (2012). A review of high-leverage teaching practices: Making connections between mathematics and foreign languages. Foreign Language Annals, 45(1), 76-97. https://doi.org/10.1111/j.1944-9720.2012.01180.x

Hußmann, S., \& Prediger, S. (2016). Specifying and structuring mathematical topics - a four-level approach for combining formal, semantic, concrete, and empirical levels exemplified for exponential growth. Journal für Mathematik-Didaktik, 37(1), 33-67.

Lamon, S. J. (2007). Proportional numbers and proportional reasoning. In F. K. Lester (Ed.), Second handbook of research on mathematics teaching and learning (pp. 629-688). Information Age Publishing.

Leong, Y. H., Tay, E. G., Toh, T. L., Quek, K. S., \& Yap, R. A. S. (2019). Concretisations: A support for teachers to carry out instructional innovations in the mathematics classroom. International Journal of Science and Mathematics Education, 17(2), 365-384. https://doi.org/10.1007/s10763-017-9868-5

Mayring, P. (2000). Qualitative content analysis. Forum Qualitative Social Sciences, 1(2), Article 20. http://www.qualitativeresearch.net/index.php/fqs/issue/view/28

Mitchell, R., Charalambous, C. Y., \& Hill, H. C. (2014). Examining the task and knowledge demands needed to teach with representations. Journal of Mathematics Teacher Education, 17(1), 37-60. https://doi.org/10.1007/s10857-013-9253-4

Ngu, B. H., Yeung, A. S., \& Tobias, S. (2014). Cognitive load in percentage change problems: unitary, pictorial, and equation approaches to instruction. Instructional Science, 42(5), 685-713. https://doi.org/10.1007/s11251-014-9309-6

Orrill, C. H., \& Brown, R. E. (2012). Making sense of double number lines in professional development: exploring teachers' understandings of proportional relationships. Journal of Mathematics Teacher Education, 15(5), 381-403.

Parker, M., \& Leinhardt, G. (1995). Percent: A privileged proportion. Review of Educational Research, 65(4), 421-481. https://doi.org/10.3102/00346543065004421

Peltenburg, M., van den Heuvel-Panhuizen, M., \& Robitzsch, A. (2012). Special education students' use of indirect addition in solving subtraction problems up to 100-A proof of the didactical potential of an ignored procedure. Educational Studies in Mathematics, 79(3), 351-369. https://doi.org/10.1007/s10649-011-9351-0 
Peltenburg, M., van den Heuvel-Panhuizen, M., \& Robitzsch, A. (2010). ICT-based dynamic assessment to reveal special education students' potential in mathematics. Research Papers in Education, 25(3), 319-334. https://doi.org/10.1080/02671522.2010.498148

Pepin, B., Xu, B., Trouche, L., \& Wang, C. (2017). Developing a deeper understanding of mathematics teaching expertise: an examination of three Chinese mathematics teachers' resource systems as windows into their work and expertise. Educational Studies in Mathematics, 94(3), 257-274. https://doi.org/10.1007/s10649-016-9727-2

Pöhler, B., \& Prediger, (2015). Intertwining lexical and conceptual learning trajectories - A design research study on dual macroscaffolding towards percentages. Eurasia Journal of Mathematics, Science \& Technology Education, 11(6), 1697-1722.

Pöhler, B., Prediger, S., \& Strucksberg, J. (2018). Prozente verstehen - Inklusive unterrichtseinheit in basis- und regelfassung [Understanding percentages - including the basic and standard version of the teaching unit]. Open Educational Resource. Retrieved from mathe-sicher-koennen.dzlm.de/100

Prediger, S., \& Buró, R. (submitted). 50 Ways to Work with Students' Diverse Abilities? A Video Study on Inclusive Teaching Practices in Secondary Mathematics Classrooms.

Prediger, S., Fischer, C., Selter, C., \& Schöber, C. (2018). Combining material- and community-based implementation strategies for scaling up: the case of supporting low-achieving middle school students. Educational Studies in Mathematics, 102(1), 361-378. https://doi.org/10.1007/s10649-018-9835-2

Prediger, S., Kuhl, J., Büscher, C., \& Buró, S. (2020). Mathematik inklusiv lehren lernen: Entwicklung eines forschungsbasierten interdisziplinären Fortbildungskonzepts [Learning to teach mathematics inclusive: Development of a research-based interdisciplinary advanced training concept]. Journal für Psychologie, 28(2), 288-312. https://doi.org/10.30820/0942-22852019-2-288

Rabardel, P. (2002). People and technology. Université Paris.

Rosenthal, L., Ilany, B.-S., \& Almog, N. (2009). Intuitive knowledge of percentages prior to learning. Research in Mathematical Education, 13(4), 297-307.

Sherin, M. G., \& Drake, C. (2009). Curriculum strategy framework: investigating patterns in teachers' use of a reform-based elementary mathematics curriculum. Journal of Curriculum Studies, 41(4), $467-500$. https://doi.org/10.1080/00220270802696115

Shreyar, S., Zolkower, B., \& Pérez, (2010). Thinking aloud together: A teacher's semiotic mediation of a whole-class conversation about percents. Educational Studies in Mathematics, 73(1), 21-53. https://doi.org/10.1007/s10649-009-9203-3

Trouche, L. (2004). Managing the complexity of human/machine interactions in computerized learning environments: Guiding students' command process through instrumental orchestrations. International Journal of Computers for Mathematical Learning, 9, Article 281.

van den Heuvel-Panhuizen, M. (2003). The didactical use of models in realistic mathematics education: An example from a longitudinal trajectory on percentage. Educational Studies in Mathematics, 54(1), 9-35.

van Galen, F., \& van Eerde, D. (2013). Solving problems with the percentage bar model. Journal on Mathematics Education, 4(1), 18. https://doi.org/10.22342/jme.4.1.558.1-8

Wilkie, K. J. (2019). The challenge of changing teaching: investigating the interplay of external and internal influences during professional learning with secondary mathematics teachers. Journal of Mathematics Teacher Education 22(1), 95-124. https://doi.org/10.1007/s10857-017-9376-0

Yin, R. K. (2002). Case study research. SAGE. 